\title{
Results of Delamination Tests of FRP- and Steel-Plate-Reinforced Larix Composite Timber $^{1}$
}

\author{
In-Hwan $\mathrm{LEE}^{2} \cdot$ Yo-Jin $\mathrm{SONG}^{2} \cdot \mathrm{Da}-\mathrm{Bin} \mathrm{SONG}^{2} \cdot$ Soon-Il HONG $\mathbb{C}^{2, \dagger}$
}

\begin{abstract}
This study evaluated the multi-bonding performances of timbers as well as those of reinforcement and timber to obtain data for preparing guidelines regarding the use of timbers as large structural members. For the multi-bonding performances of timbers, four types of bonding surfaces were prepared according to the pith position. For the bonding performances of FRP (fiber-reinforced plastic)/steel plate and timber, a total of 11 types of specimens were produced for the selection of the appropriate adhesive. The bonding performances of the produced specimens were evaluated through a water soaking delamination test, a water boiling delamination test, and a block shear strength test. The test results showed that the bonding strength of the bonding surface according to the pith position was highest in the specimen for which the two sections with the pith at the center of the cross-section on timber and between the bonding surfaces (the tangential and radial sections were mixed) were bonded. Furthermore, the specimens for which the section (radial section) with the pith on the bonding surface of the timber was bonded showed a high delamination percentage. The results of the block shear strength test showed that the bonding section did not have a significant effect on the shear strength, and that the measured wood failure percentage was higher than the KS standard value. The PVAc adhesive showed the highest bonding strength between larix timber and GFRP (glass FRP). Furthermore, the epoxy and polyurethane adhesives showed good bonding strength for CFRP (carbon FRP) and structure steel, respectively.
\end{abstract}

Keywords: bonding performance, composite timber, CFRP, GFRP, steel plate, shear strength, delamination percentage

\section{INTRODUCTION}

Thinning is essential for afforestation for economic species improvement and silviculture, but the industry is not actively engaging in timber production through thinning because the timbers produced through thinning are mainly used in low-value-added industries (Underhill, 2016). Composite timbers that have laminated and reinforced timbers produced from small- diameter wood, however, can minimize strength variations and can be used for large structural members with no sectional area limitation. Producing timbers from large solid wood will cost much, but it has an economic value if multi-layer composite timber is produced by laminating timbers. Song et al. (2016) reported that the cross-laminated timber (CLT) produced in their study using the same species and adhesive showed a lower block shear strength (0.36 times) and a higher

\footnotetext{
${ }^{1}$ Date Received May 14, 2019, Date Accepted September 5, 2019

2 Timber Engineering Lab., Division of Forest Material Science \& Engineering, Program of Forest materials Engineering, College of Forest and Environmental Sciences, Kangwon National University

† Corresponding author: Soon-Il HONG (e-mail: hongsi@kangwon.ac.kr, ORCID: 0000-0002-9627-2208)
} 
delamination percentage than glulam. The composite timber with laminated timbers includes pith and juvenile wood, and its moisture content and section size are different from those of the glulam produced from lumber. Timbers are expected to show a bonding performance different from that of lumber, and to show different bonding performances according to the bonding section. The bonding performance evaluation of timbers is indispensable, but the related research is insufficient.

Kim et al. (2012) considered that timbers are likely to be produced as laminated timber and used as columns or beams rather than as single members, and distinguished the physical properties of timbers. Lee et al. (2018) produced a domestic larix timber and reinforced the outermost tensile part where the tensile stress is concentrated with fiber-reinforced plastics (FRPs); they also compared its strength performance with that of a glulam with the same modulus of section. As a result, the timbers reinforced with CFRP (carbon FRP) and GFRP (glass FRP) showed 32 and 8\% larger flexural strengths on average, respectively. Jung et al. (2016) evaluated moment resistance performance reinforced with GFRP and GFRP rods. Schober et al. (2005) produced three types of specimens whose outermost tensile part was reinforced with CFRP using an epoxy adhesive, and reported that the specimens showed improved strength. Shi et al. (2017) produced glulams using GFRP and calculated the strength of each lumber layer. The domestically produced timbers can have bonding performances different from those of the reinforcements. Thus, test results for timbers reinforced with FRP and steel plate are required.

In this study, the lumber-lumber and reinforcementlumber bonding performances were evaluated for each pith position. The specimens for the lumber-lumber bonding performance test were produced using different bonding surfaces, compressive pressures, and adhesive amounts. The specimens for the timber-reinforcement bonding performance test, on the other hand, were produced with five adhesive and three reinforcement types.

\section{MATERIALS and METHODS}

\subsection{Testing materials}

For the testing materials, domestic larix (Larix kaemferi Carr.) timbers $(89 \times 120 \times 3600 \mathrm{~mm})$ were used, and for the reinforcements, 3-mm-thick GFRP and 1.3-mm-thick CFRP and 1.5-mm- thick structure steel(hot rolled steel sheets(CR KS SCP1)) were used (Fig. 1). FRP reinforcements were produced through the pultrusion of glass or carbon fibers using an epoxy adhesive (Fig. 2). Five adhesive types were used for the timber and reinforcement: PRF (phenol-resorcinol-

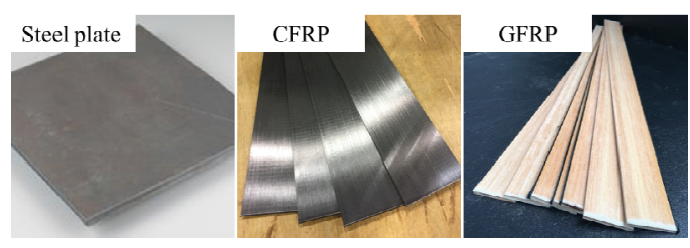

Fig. 1. Photographs of the reinforcements used in this study.

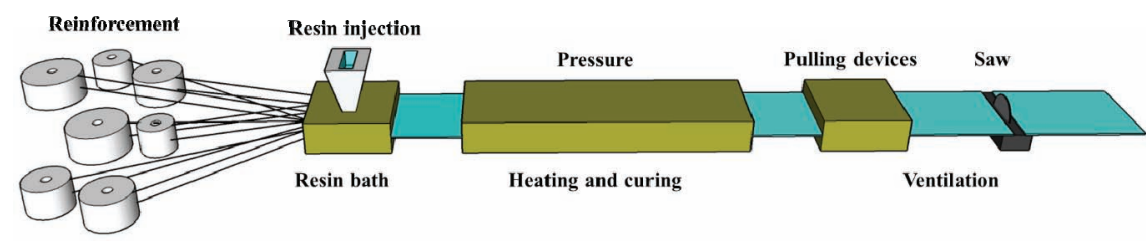

Fig. 2. Pultrusion process. 
Table 1. Information and properties of adhesives

\begin{tabular}{cccccc}
\hline Adhesive & Color & $\begin{array}{c}\text { Specific } \\
\text { gravity }\end{array}$ & $\begin{array}{c}\text { Assembly time } \\
(\mathrm{min})\end{array}$ & Viscosity (cPs) & $\begin{array}{c}\text { Mix ratio } \\
\text { (resin:hardener) }\end{array}$ \\
\hline \hline PRF & Reddish brown & 1.2 & $120\left(25^{\circ} \mathrm{C}\right)$ & $300-1,000$ & $10: 1.5$ \\
Polyurethane & Light beige & 1.2 & $20\left(23^{\circ} \mathrm{C}\right)$ & $\sim 2,000$ & 1 -component \\
PVAc & Ivory white & 1.1 & $60\left(30^{\circ} \mathrm{C}\right)$ & $6,000-7,500$ & $10: 1$ \\
Epoxy-A & Light grey & 1.8 & $90\left(20^{\circ} \mathrm{C}\right)$ & Thixotrophy & $3: 1$ \\
Epoxy-B & Transparent color & 1.2 & $30\left(23^{\circ} \mathrm{C}\right)$ & $11,000-15,000$ & $10: 5$ \\
\hline
\end{tabular}

formaldehyde), polyurethane, poly-vinyl acetate, and two types of epoxy adhesives. The properties of the adhesives are listed in Table 1.

\subsection{Production of bonding performance specimens for larix timber}

\subsubsection{Production of specimens for the lumber-lumber bonding performance test}

The bonding surface of timber appears different depending on the pith position, and the bonding performance will vary by bonding surface. Thus, in this study, specimens were prepared with four types of bonding surface between timbers, as follows. The first specimen was produced by bonding two tangential sections of the bonding surfaces where the pith was located at the center of the timber (Fig. 3 - Type I). The second specimen was produced by bonding the tangential and radial sections of the bonding surfaces where the pith was located between the center and the bonding surface (Fig. 3 - Type II). The third specimen was produced by bonding the radial and tangential sections of the bonding surfaces where the pith was located on the bonding surface (Fig. 3 - Type III). The fourth specimen was produced by bonding a mixed section of tangential and radial sections with a radial section (Fig. 3 - Type IV).

For the modulus of elasticity of the timber, the 8-10 GPa range was used, which was determined through the non-destructive longitudinal vibration method. PRF

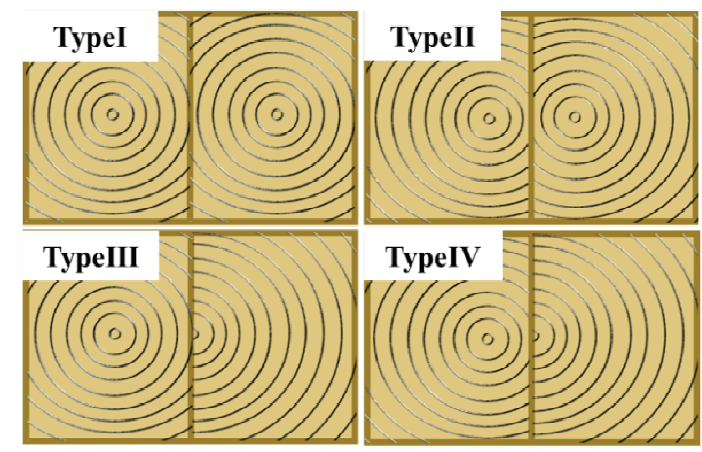

Fig. 3. Schematic diagram by delamination specimen type.

(phenol-resorcinol formaldehyde resin) adhesive was applied to all the specimens at $300 \mathrm{~g} / \mathrm{m}^{2}$, and the specimens were cured at room temperature at $1 \mathrm{MPa}$ compressive pressure for 24 hours. The specimens of bonded timbers were cut to the length of $75 \mathrm{~mm}$ in accordance with KS F 2160, and a total of 80 water soaking and boiling delamination specimens were produced, with 10 specimens for each bonding surface type.

The block shear specimens were produced with the same bonding surface types as in the delamination test, in accordance with KS F 3021. A total of 40 specimens were produced, with 10 specimens for each bonding surface type. For this test, the specimens were fixed in the universal testing system Instron 4482, and a load was applied at 9,800 N/mm until failure, in accordance with KS F 3021. After the block shear strength test, the failed sections of the specimens were captured and 


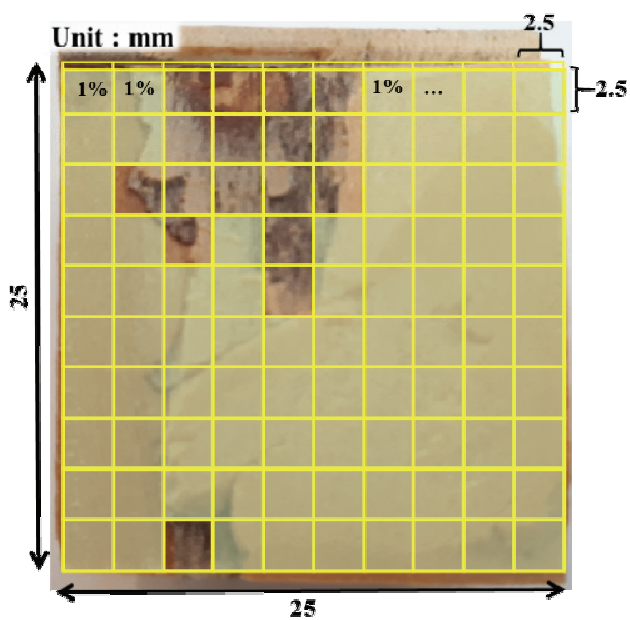

Fig. 4. Photograph of wood failure.

divided into 100 grids. Then the wood failure percentage was determined by measuring the failed part (Fig. 4).

For the bonding surface types that showed the best bonding strength in the delamination and block shear strength tests, better bonding conditions were examined by changing the adhesive amount and compressive pressure. Four specimen types were produced, with 300 and $400 \mathrm{~g} / \mathrm{m}^{2}$ adhesive amounts and 1 and $1.5 \mathrm{MPa}$ compressive pressures. A total of 40 specimens were produced, with 5 specimens for each type.

\subsubsection{Production of specimens for the reinforcement-lumber bonding performance test}

For the reinforcement-lumber bonding performance test, 11 specimen types were produced, as shown in Table 2. For the epoxy-A, polyurethane, and polyvinyl acetate adhesives, the appropriate adhesive amount was set to $300 \mathrm{~g} / \mathrm{m}^{2}$ for the specific gravity of $1.2-1.3$ (Lee et al., 2016). The epoxy-B adhesive was applied at $500 \mathrm{~g} / \mathrm{m}^{2}$ because it had a smaller volume at the same adhesive amount as the specific gravity was 1.8. A total of 110 specimens were produced, with 10 specimens for each type. The water soaking and delamination tests were conducted in accordance with KS F 2160.

\section{RESULTS and DISCUSSION}

\subsection{Results of the lumber-lumber bonding performance test}

\subsubsection{Results of the water soaking and boiling delamination tests}

When timber under the fiber saturation point (FSP)

Table 2. Type of resistance to water soaking and boiling-water soaking delamination

\begin{tabular}{|c|c|c|c|c|}
\hline $\begin{array}{c}\text { Reinforcement } \\
\text { type }\end{array}$ & $\begin{array}{l}\text { Specimen } \\
\text { type }\end{array}$ & Adhesive & $\begin{array}{l}\text { Adhesive amount } \\
\left(\mathrm{g} / \mathrm{m}^{2}\right)\end{array}$ & $\begin{array}{c}\text { Curing period } \\
\text { (day) }\end{array}$ \\
\hline \multirow{4}{*}{ GFRP } & Type 1 & Epoxy-B & 300 & \multirow{10}{*}{3} \\
\hline & Type 2 & Epoxy-A & 500 & \\
\hline & Type 3 & Polyurethane & \multirow{3}{*}{300} & \\
\hline & Type 4 & PVAc & & \\
\hline \multirow{2}{*}{ CFRP } & Type 5 & Epoxy-B & & \\
\hline & Type 6 & Epoxy-B & \multirow{2}{*}{500} & \\
\hline \multirow{5}{*}{ Steel } & Type 7 & Epoxy-B & & \\
\hline & Type 8 & Polyurethane & \multirow{4}{*}{300} & \\
\hline & Type 9 & Epoxy-A & & \\
\hline & Type 10 & PVAc & & \\
\hline & Type 11 & PVAc & & 7 \\
\hline
\end{tabular}




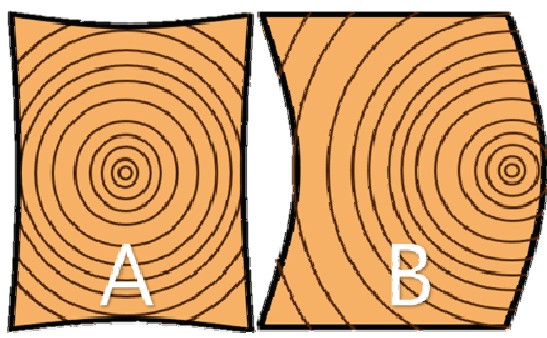

Fig. 5. Schematic diagram of dry shrinkage deformation by pith position.

is dried, drying stress occurs inside the timber. During the drying, constant-rate drying occurs in the surface layer. In the inner layer, compressive stress occurs on the surface of the timber, and tensile stress occurs inside, because the moisture moves to the surface layer. In general, the heartwood that is close to the pith has bound water, and the aspirated pith has a higher moisture content than the sapwood due to the former's slow moisture movement (McMillen, 1958). Therefore, the closer the timber surface is to the pith, the slower the drying becomes. Thus, when the pith is located close to the surface layer, one side appears shrunken and the other side appears inflated. For timber where the pith is at the center, it is expected that the four sides will shrink uniformly (Fig. 5). The above theory was applied to the delamination specimens, and the delamination specimens were actually deformed, as shown in Fig. 6.
According to the results of the water soaking delamination test, the delamination percentages of specimen types I and II were lower than those of the other specimens. Specimen type III showed a relatively low bonding strength. As shown by the results of the boiling delamination test, the delamination percentage of type II was the lowest, and types III and IV showed low bonding strengths. Specimen type II satisfied the passing criteria for both the water soaking and delamination tests, and showed the lowest delamination percentage. Specimen type III failed to meet the passing criteria in both tests. In every specimen type, the existence of delamination before the test did not affect the delamination percentage, and each specimen type showed a different delamination location. For specimen type I, the delamination started from the center of the glue line. Specimen type II showed a low delamination percentage at the center or both ends of the glue line. For specimen types III and IV, large delamination occurred in the opposite glue line, where the pith existed. The reason for this is the dry deformation of lumber. When there is a pith, cup-shaped deformation occurs. In the case of heartwood with a pith, it is shrunk towards the center, resulting in a difference in stress between two different timbers (Fig. 5). Therefore, the water resistance will be greater if the larix timbers are bonded with their piths closer to each other, and direct bonding of the radial sections should be avoided. Consequently,
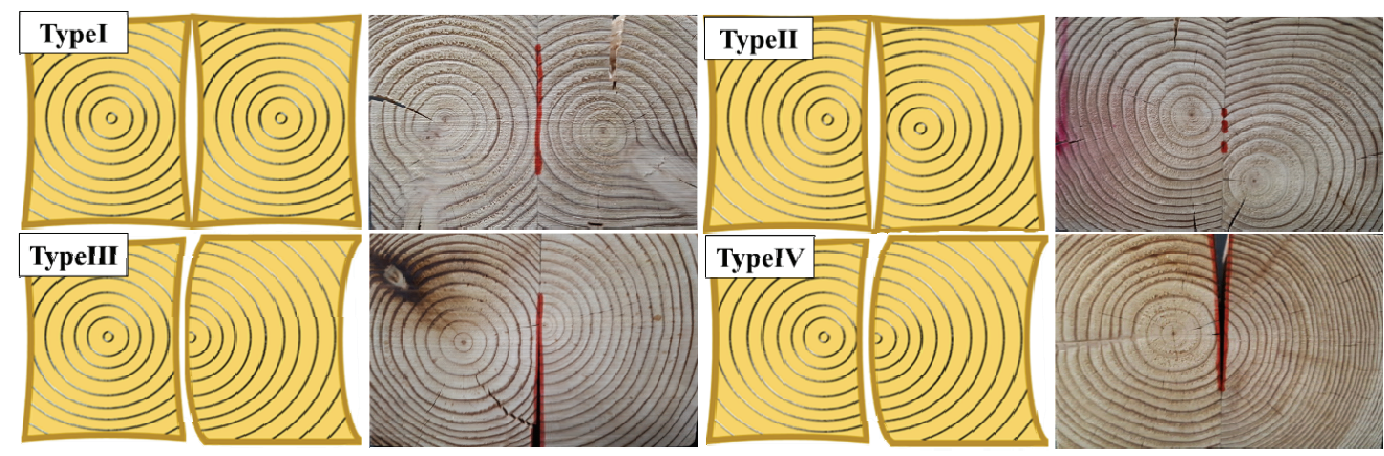

Fig. 6. Shrinkage deformation prediction schematic diagram and photograph. 
the average delamination percentages of the different specimen types in the water soaking delamination test were $7.51,2.11,1.83$, and $1.95 \%$. Thus, all the specimens satisfied the passing criterion of $5 \%$ or lower in KS F 3021, except for specimen type I. The average delamination percentages of the different specimen types in the boiling delamination test were $8.51,1.28$, 15.11, and $8.29 \%$. Thus, only specimen type II satisfied the passing criterion.

\subsubsection{Results of the block shear strength test}

The average shear strengths of specimen types I-IV produced with the PRF adhesive were 10.7, 9.2, 10.8, and 11.4 MPa, respectively. Thus, all the specimen types satisfied the passing criterion of 7.1 MPa or higher in KS F 3021. The wood failure percentages were 85.22, 78.78, 79,11, and $87 \%$, which also satisfied the passing criterion of $65 \%$ or higher. Regardless of the bonding type, all the specimens showed a failure tendency along the annual rings as the failure occurred in the springwood part, which has a lower specific gravity than the summerwood part. Hence, the shear strength of the timber was unrelated to the bonding according to the pith position. Specimen type II was subjected to the water soaking and boiling delamination tests according to the adhesive amount and compressive pressure.

\subsubsection{Results of the water soaking and boiling delamination tests according to the adhesive amount and compressive pressure}

The type II water soaking delamination specimens showed $1.26,0.52,0$, and $0 \%$ delamination percentages for the 300 and $400 \mathrm{~g} / \mathrm{m}^{2}$ adhesive amounts, thus satisfying the passing criterion of lower than 5\%. All the specimens satisfied the passing criterion of KS F 2160, and the specimens produced with $1.5 \mathrm{MPa}$ compressive pressure showed higher bonding strength than the specimens produced with $1 \mathrm{MPa}$ compressive pressure.
The type II boiling delamination specimens showed 1.38 and $1.35 \%$ delamination percentages for the 300 and $400 \mathrm{~g} / \mathrm{m}^{2}$ adhesive amounts, respectively. The specimens produced with 1.5 MPa compressive pressure also showed 0.6 and $0 \%$ delamination percentages for the 300 and $400 \mathrm{~g} / \mathrm{m}^{2}$ adhesive amounts. Thus, all the boiling delamination test specimens satisfied the passing criterion of lower than 5\% in KS F 2160. In the boiling delamination test, the delamination percentage of all the specimens decreased as the adhesive amount and compressive pressure increased. The specimen produced with $1.5 \mathrm{MPa}$ compressive pressure and a $400 \mathrm{~g} / \mathrm{m}^{2}$ adhesive amount showed no boiling delamination percentage, thus satisfying the KS standard.

\subsection{Reinforcement-lumber bonding strength performance evaluation results}

Table 3 shows the results of the reinforcement-larix timber delamination test. All the specimens showed different results according to the reinforcement and adhesive types. All the specimens bonded with GFRP as reinforcement (type 1-4 specimens), except for those bonded with the epoxy-A adhesive, satisfied the passing criterion of $5 \%$ for the water soaking and boiling delamination percentages in the KS standard. In the case of the type 2 specimens bonded with epoxy-B, some specimens showed cracks during drying. No delamination was observed in the glue line, however, but the cracks occurred together in the reinforcement and timber as they were integrated.

The polyurethane (Ottocoll P84) adhesive is a foaming adhesive, and when it is applied for bonding reinforcement and timber, fine pores are inevitably created between the two (Fig. 7A). These pores were marked in advance in this study, and were not applied to the delamination percentage. The delamination of the glue line excluding the pores was observed to be less than $3 \mathrm{~mm}$; thus, it was not applied to the delamination 
Table 3. Resistance to water soaking and boiling-water soaking delamination

\begin{tabular}{|c|c|c|c|c|}
\hline \multirow{2}{*}{$\begin{array}{l}\text { Specimen } \\
\text { type }\end{array}$} & \multicolumn{2}{|c|}{$\begin{array}{c}\text { Delamination after water soaking } \\
(\%)\end{array}$} & \multicolumn{2}{|c|}{$\begin{array}{c}\text { Delamination after boiling-water soaking } \\
(\%)\end{array}$} \\
\hline & Mean & $\mathrm{COV}$ & Mean & $\mathrm{COV}$ \\
\hline Type 1 & 3.2 & 4.54 & 100 & 0 \\
\hline Type 2 & 0 & 0 & 0.8 & 0 \\
\hline Type 3 & 0.61 & 1.06 & 0 & 1.06 \\
\hline Type 4 & 0 & 0 & 0 & 0 \\
\hline Type 5 & 5.8 & 5.2 & 100 & 0 \\
\hline Type 6 & 0.62 & 1.39 & 0 & 1.39 \\
\hline Type 7 & 100 & 0 & - & - \\
\hline Type 8 & 0 & 0 & 0 & 0 \\
\hline Type 9 & 56.17 & 23.8 & - & - \\
\hline Type 10 & 0 & 0 & 100 & 0 \\
\hline Type 11 & 0 & 0 & 100 & 0 \\
\hline
\end{tabular}

*COV: Coefficient of variation

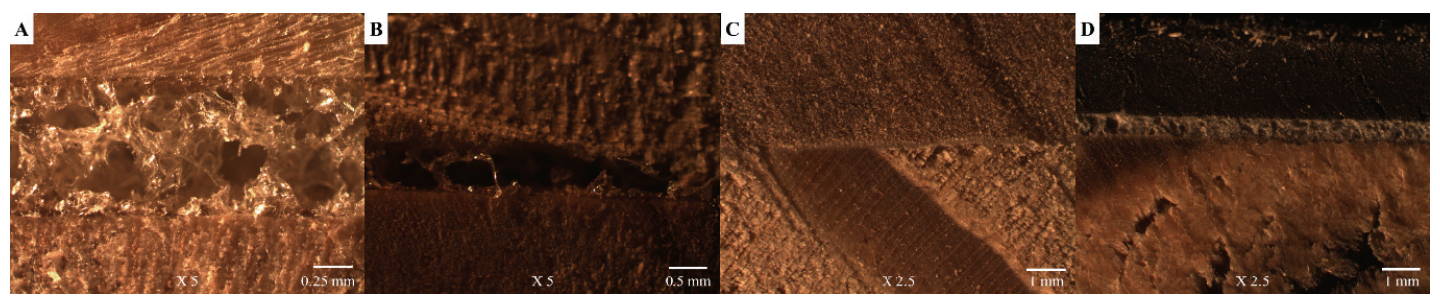

Fig. 7. Photograph of the boiling-water soaking delamination specimens.

percentage (Fig. 7B). Among the specimens bonded with GFRP as reinforcement, the type 4 specimens produced with the PVAc adhesive showed the best delamination percentage because no water soaking and boiling delaminations were observed in them (Fig. 7C).

Among the specimens bonded with CFRP as reinforcement (type 5 and 6 specimens), the type 5 specimens failed to pass both the water soaking and boiling delamination percentage criteria. The type 5 specimens produced with the epoxy-B adhesive showed good results for both the water soaking and boiling delamination percentages. Some type 6 specimens showed large distortions during drying after the boiling delamination test, but no delamination was observed, indicating excellent bonding strength (Fig. 7D).
Among the specimens bonded with structure steel as reinforcement (type 7-11 specimens), the type 7 and 9 specimens produced with the epoxy adhesive failed to pass the water soaking delamination percentage criterion of the KS standard. Thus, the boiling delamination test, which has more severe conditions, was not performed. In the case of the type 10 specimens, which were produced by bonding structural steel and timber with the PVAc adhesive, the water soaking delamination percentage was good, but the boiling delamination percentage (100\%) failed to pass the KS standard criterion. The production process of the type 11 specimens was the same as that of the type 10 specimens. An additional test was performed by resetting the curing period to 7 days, but the resulting boiling delamination percentage 
was $100 \%$, indicating poor bonding performance. When the structural steel and timber were bonded with polyurethane (type 8 specimens), however, the specimens were not delaminated under any condition, indicating excellent bonding strength.

\section{CONCLUSION}

For the bonding performance of the bonding surface between larix timbers according to the pith position, the bonding strength was lowest when a radial section whose pith was on the bonding surface was bonded, and the bonding performance was excellent when the pith was between the center and the bonding surface. In the block shear strength test, however, all the specimen types satisfied the KS standard regardless of the pith position.

The bonding strength between the larix timber and the GFRP (glass fiber-reinforced plastic) reinforcement was good when the epoxy-B, polyurethane, and PVAc adhesives were used to bond them. In particular, the specimen produced with the PVAc adhesive showed the highest bonding strength. Among the specimens bonded with CFRP reinforcement, those produced with the epoxy-B adhesive showed the best bonding performance. The specimens produced by bonding structural steel and timber with polyurethane showed no delamination percentage in the water soaking and boiling delamination tests.

\section{ACKNOWLEDGMENT}

This study was conducted as a basic research project supported by Korea Research Foundation with funding from the government (Ministry of Education) in 2016 (No. R1D1A1B01011163).

\section{REFERENCES}

Jung, H.J., Song, Y.J., Lee, I.H., Hong, S.I. 2016. Moment resistance performance evaluation of larch glulam joints using GFRP-reinforced laminated plate and GFRP rod. Journal of the Korean Wood Science and Technology 44(1): 40-47.

Kim, Y.H., Shin, I.J., Yang, J.M., Jang, S.S. 2012. Allowable Stress Calculation of Domestic Japanese Larch Small Diameter Lumbers. Journal of the Korea Furniture Society 23(2): 214-221.

Korean Standards Association. 2013. KS F 3021. Structural glued laminated timber.

Korean Standards Association. 2013. KS F 2160. Delamination of resistance to soaking delamination for adhesive-bonded wood products.

Lee, I.H., Park, J.H., Song, D.B., Hong, S.I. 2018. Longitudinal Bonding Strength Performance Evaluation of Larch Lumber. Journal of the Korean Wood Science and Technology 46(1): 85-92.

Schober, K.U., Rautenstrauch, K. 2005. December. Experimental investigations on flexural strengthening of timber structures with CFRP. In Proceedings of the International Symposium on Bond Behaviour of FRP in Structures (BBFS 2005), pp. 457-464 Shi, H., Liu, W., Fang, H., Bai, Y., Hui, D. 2017. Flexural responses and pseudo-ductile performance of lattice-web reinforced GFRP-wood sandwich beams. Composites Part B: Engineering 108: 364-376.

Song, Y.J., Hong, S.I. 2016. Evaluation of bonding strength of larch cross-laminated timber. Journal of the Korean Wood Science and Technology 44(4): 607-615. 